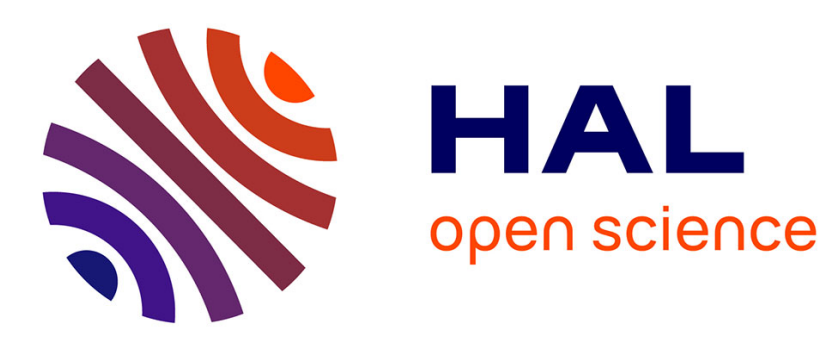

\title{
Suppression of $\alpha$-synuclein propagation after intrastriatal injection in FABP3 null mice
}

Kazuya Matsuo, Ichiro Kawahata, Ronald Melki, Luc Bousset, Yuji Owada, Kohji Fukunaga

\section{- To cite this version:}

Kazuya Matsuo, Ichiro Kawahata, Ronald Melki, Luc Bousset, Yuji Owada, et al.. Suppression of $\alpha$-synuclein propagation after intrastriatal injection in FABP3 null mice. Brain Research, 2021, 1760, pp.147383. 10.1016/j.brainres.2021.147383 . cea-03174556

\section{HAL Id: cea-03174556 https://hal-cea.archives-ouvertes.fr/cea-03174556}

Submitted on 19 Mar 2021

HAL is a multi-disciplinary open access archive for the deposit and dissemination of scientific research documents, whether they are published or not. The documents may come from teaching and research institutions in France or abroad, or from public or private research centers.
L'archive ouverte pluridisciplinaire HAL, est destinée au dépôt et à la diffusion de documents scientifiques de niveau recherche, publiés ou non, émanant des établissements d'enseignement et de recherche français ou étrangers, des laboratoires publics ou privés. 
${ }^{1}$ Suppression of $\alpha$-synuclein propagation after intra-striatal injection in FABP3 null mice

Kazuya Matsuo ${ }^{1}$, Ichiro Kawahata ${ }^{1}$, Ronald Melki ${ }^{2}$, Luc Bousset ${ }^{2}$, Yuji Owada ${ }^{3}$, Kohji Fukunaga $^{1 *}$

${ }^{1}$ Department of Pharmacology, Graduate School of Pharmaceutical Sciences, Tohoku University, Sendai, 980-8578, Japan

${ }^{2}$ CEA, Institut François Jacob (MIRcen) and CNRS, Laboratory of Neurodegenerative Diseases, 18 Route du Panorama, 92265 Fontenay-aux-Roses, France

${ }^{3}$ Department of Organ Anatomy, Graduate School of Medicine, Tohoku University, Sendai, 980-0872, Japan

*Author to whom correspondence should be addressed.

E-mail: kazuya.matsuo.q8@dc.tohoku.ac.jp (K.M.); kawahata@tohoku.ac.jp (I.K.) Luc.BOUSSET@cnrs.fr (L.B.); ronald.melki@cnrs.fr. (R.M.);owada@med.tohoku.ac.jp

\footnotetext{
${ }^{1}$ Abbreviations: AA, arachidonic acid; ANOVA, analysis of variance; DLB, dementia with Lewy bodies; FABP, fatty acid-binding protein; LB, Lewy body; LC-PUFA, longchain polyunsaturated fatty acid; LN, Lewy neurite; MPTP, 1-methyl-1,2,3,6tetrahydropyridine; PD, Parkinson's disease; SNpc, substantia nigra pars compacta; paSyn, phosphorylated $\alpha$ Syn; TH, tyrosine hydroxylase; VTA, ventral tegmental area; $\alpha$ Syn, $\alpha$-synuclein
} 
(Y.O.);kfukunaga@m.tohoku.ac.jp (K.F.)

Tel: 81-22-795-6838

Fax: 81-22-795-6835 


\begin{abstract}
Accumulation and aggregation of $\alpha$-synuclein ( $\alpha \mathrm{Syn})$ triggers neuronal loss in the substantia nigra pars compacta ( $\mathrm{SNpc}$ ) which in turn causes motor symptoms in Parkinson's disease. We previously demonstrated that fatty acid-binding protein 3 (FABP3), an intracellular fatty acid carrier protein, enhances $\alpha$ Syn neurotoxicity in the SNpc and motor impairments after intranigral injection of $\alpha$ Syn fibrils. However, temporal spreading profile of $\alpha$ Syn fibrils and those toxicity remains unclear. In the present study, we investigated the temporal profile of $\alpha$ Syn fibrils and its toxicity inducing intracellular fibril formation. Monomeric and fibrillar aSyn assemblies were labelled with ATTO550 to distinguish exogenous from endogenous species and injected into bilateral striatum in $\mathrm{Fabp3}^{+/+}$(wild type) and $\mathrm{Fabp3}^{-/-}$mice. Accumulation of both monomeric and fibrillar exogenous $\alpha \mathrm{Syn}$ in the SNpc was drastically decreased in $\mathrm{Fabp3}^{-/-}$mice compared to $\mathrm{Fabp3}^{+/+}$counterparts. Fabp3 deletion also prevented exogenous $\alpha$ Syn fibrils-induced seeding of endogenous $\alpha$ Syn into aggregation containing phosphorylated and filament forms in the SNpc. Consistent with these results, loss of dopaminergic neurons and the following impaired motor behaviours were attenuated in $\mathrm{Fabp}^{3 /-}$ mice. These results highlight crucial role of FABP3 in pathogenic $\alpha$ Syn accumulation and its seeding ability. Taken together, FABP3 could be a potential therapeutic target against $\alpha$ Syn propagation in synucleinopathies.
\end{abstract}

Keywords: $\alpha$-Synuclein; Lewy body disease; FABP3; dopaminergic neurons 


\section{Introduction}

$\alpha$-synuclein ( $\alpha$ Syn) is a main component of Lewy bodies (LBs) and Lewy neurites (LNs) in synucleinopathies including Parkinson's disease (PD) and dementia with Lewy bodies (DLB) (Spillantini et al., 1997). While $\alpha$ Syn is mainly localized at presynaptic terminals as unstructured monomers (Maroteaux et al., 1988; Diao et al., 2013), the protein shifts to oligomeric, fibrillar, and aggregated forms upon factors including oxidative stress and aging (Qin et al., 2007; Canron et al., 2012). These misfolded $\alpha$ Syn strains exert toxicity and lead to loss of dopaminergic neurons in the substantia nigra pars compacta (SNpc) and the resultant motor impairments (Winner et al., 2011; Shioda et al., 2014).

Transplantation of embryonic nigral dopaminergic neurons into PD patients revealed that $\alpha$ Syn-positive LB inclusions were observed in grafted embryonic neurons (Kordower et al., 2008), suggesting $\alpha$ Syn has a property of transcellular propagation in a prion-like manner. Pathological $\alpha$ Syn also spreads throughout brain and the spreading pattern may overlap with disease-stage development in patients with synucleinopathies (Braak et al., 2001; Braak et al., 2003). These prion-like $\alpha$ Syn propagation is partly reproducible in experimental models. Intracerebral injection of $\alpha$ Syn fibrils in rodents demonstrated transcellular propagation of the exogenous template and seeding of endogenous soluble $\alpha$ Syn into LNs and LB-like inclusions (Paumier et al., 2015; Peelaerts et al., 2015). The seeded propagation and the spatiotemporal spreading likely depend on such as neuronal connectivity and endogenous $\alpha$ Syn expression levels (Erskine et al., 2018; Okuzumi et al., 2018; Henderson et al., 2019); however, critical molecular mechanisms underlying these $\alpha$ Syn pathology remain unknown.

Long-chain polyunsaturated fatty acids (LC-PUFAs) such as arachidonic acid

(AA) and docosahexaenoic acid (DHA) are a factor affecting $\alpha$ Syn 
aggregation/oligomerization. LC-PUFAs directly bind with $\alpha$ Syn and promote its oligomerization in vitro (Perrin et al., 2001; Sharon et al., 2003). DHA-rich diets aggravate $\alpha$ Syn oligomerization and synapse loss in human A53T $\alpha$ Syn transgenic mice (Yakunin et al., 2012). LC-PUFAs are solubilized and intracellularly transported by carrier proteins termed fatty acid-binding proteins (FABPs) (Coe and Bernlohr, 1998). Among 10 FABP family in mammals, FABP3 highly expresses in neurons, particularly in dopaminergic neurons in the SNpc, at adult stage (Owada et al., 1996; Hertzel and Bernlohr, 2000; Shioda et al., 2014). The FABP3 levels in serum and cerebrospinal fluid were increased in patients with synucleinopathies (Mollenhauer et al., 2007; Wada-Isoe et al., 2008; Chiasserini et al., 2017).

To clarify role of FABP3 in $\alpha$ Syn pathology, we previously investigated effects of Fabp3 deletion on dopamine neurotoxicity induced by 1-methyl-1,2,3,6tetrahydropyridine (MPTP). We found that FABP3 binds to $\alpha$ Syn to make oligomers upon MPTP treatment, and Fabp3 $3^{-/-}$mice were resistant to MPTP-induced motor impairments (Shioda et al., 2014). We further demonstrated a novel FABP3-selective ligand that competitively inhibits AA binding to FABP3 (Cheng et al., 2019) antagonizes $\alpha$ Syn oligomerization in MPTP-treated mice (Matsuo et al., 2019). The FABP3 ligand also attenuated phosphorylated $\alpha$ Syn (paSyn) deposits caused by intranigral injection of $\alpha$ Syn fibrils (Yabuki et al., 2020); however, it remains unclear how FABP3 contributes to spreading of exogenously applied $\alpha$ Syn and the seeding of endogenous $\alpha$ Syn into inclusions.

Using fluorophore (ATTO550)-labelled aSyn fibrils, we here investigated the temporal profile of $\alpha$ Syn propagation after intrastriatal injection of $\alpha$ Syn strains (monomers and fibrils). Accumulation of ATTO-positive exogenous $\alpha$ Syn was drastically 
suppressed in the SNpc of Fabp $3^{-/-}$mice. Fabp $3^{-/-}$mice were also resistant to formation of LB-like inclusions and loss of dopaminergic neurons, thereby maintained normal motor behaviours. 


\section{Results}

\subsection{Accumulation of exogenous $\alpha \mathrm{Syn}$ was prevented in the SNpc of $\mathrm{Fabp3}^{-{ }^{--}}$mice}

We previously reported that Fabp3 deletion decreased intracellular levels of exogenous monomeric $\alpha$ Syn in primary mesencephalic cultures (Kawahata et al., 2019). To further clarify effects of FABP3 on temporal accumulation of exogenous $\alpha$ Syn in nigral dopaminergic neurons in vivo, sections from $\mathrm{Fabp3}^{+/+}$and $\mathrm{Fabp3}^{-/-}$were prepared after bilaterally intrastriatal $\alpha$ Syn injection (Fig. 1). When monomeric $\alpha$ Syn was injected into the dorsal striatum, two-way ANOVA revealed significant effects of genotype $\left(\mathrm{F}_{(1,40)}=\right.$ 45.45, $\mathrm{p}<0.01)$, time $\left(\mathrm{F}_{(4,40)}=27.34, \mathrm{p}<0.01\right)$, and genotype $\mathrm{x}$ time $\left(\mathrm{F}_{(4,40)}=17.28, \mathrm{p}\right.$ $<0.01)$ on ATTO/tyrosine hydroxylase $(\mathrm{TH})$ area ratio (Fig. 2A). Intracellular levels of exogenous $\alpha$ Syn peaked at 1 day after the injection then rapidly decreased in $\mathrm{Fabp}^{+/+}$ mice (Fig. 2A). By contrast, the transient accumulation of exogenous $\alpha$ Syn was not observed in Fabp3 $3^{-/-}$mice ( 1 day: $\mathrm{p}<0.01$ vs. Fabp3 $3^{+/+}$mice; Fig. 2A), in line with our previous observation in primary mesencephalic cultures (Kawahata et al., 2019). Fibrillar $\alpha$ Syn injection also showed significant effects of genotype $\left(F_{(1,40)}=57.46, p<0.01\right)$, time $\left(\mathrm{F}_{(4,40)}=5.06, \mathrm{p}<0.01\right)$, and genotype $\mathrm{x}$ time $\left(\mathrm{F}_{(4,40)}=6.51, \mathrm{p}<0.01\right)$ on ATTO/TH area ratio (Fig. 2B). ATTO-positive exogenous $\alpha$ Syn fibrils were gradually accumulated in $\mathrm{Fabp3}^{+/+}$mice over the time course, though the levels were lower compared to those of aSyn monomers (Fig. 2B). Fabp3 deletion also prevented accumulation of $\alpha$ Syn fibrils in nigral dopaminergic neurons ( 3 day: $\mathrm{p}<0.05 ; 10$ day: $\mathrm{p}<0.01 ; 30$ day: $\mathrm{p}<0.01$ vs. Fabp $^{+/+}$mice; Fig. 2B).

We also probed sections with anti-paSyn at S129-specific antibody to confirm the effect of accumulation of exogenous $\alpha$ Syn assemblies on formation of LB-like 
inclusions. While monomeric $\alpha$ Syn injection failed to form paSyn-positive inclusions over the time course (Fig. 2A), 10 days were enough to induce LB-like inclusions, which were further maturated at 30 days after fibrillar $\alpha$ Syn injection (Fig. 2B). At 30 days after the injection, a relatively small fraction of paSyn-positive inclusions was observed also in $\mathrm{Fabp3}^{-/-}$mice (Fig. 2B).

\subsection{Fabp3 deletion attenuated exogenous $\alpha$ Syn fibril-induced neurotoxicity}

We next confirmed effects of Fabp3 deletion on loss of nigral dopaminergic neurons induced by intrastriatal $\alpha$ Syn injection (Fig. 3A). When quantified TH-positive neurons in the SNpc over the same time course, three-way ANOVA detected significant differences in genotype $\left(\mathrm{F}_{(1,80)}=8.27, \mathrm{p}<0.01\right)$, strain $\left(\mathrm{F}_{(1,80)}=33.98, \mathrm{p}<0.01\right)$, genotype $\mathrm{x}$ strain $\left(\mathrm{F}_{(1,80)}=5.18, \mathrm{p}<0.05\right)$, strain $\mathrm{x}$ time $\left(\mathrm{F}_{(4,80)}=3.90, \mathrm{p}<0.01\right)$, genotype $\mathrm{x}$ strain $\mathrm{x}$ time $\left(\mathrm{F}_{(4,80)}=2.77, \mathrm{p}<0.05\right)$. Fibrillar $\alpha$ Syn injection in $\mathrm{Fabp}^{+/+}$mice tended to induce loss of TH-positive neurons at 10 days ( $p=0.052$ vs. monomer-injected Fabp $3^{+/+}$mice; Fig. 3B), the time point when paSyn-positive inclusions were begun to form (Fig. 2B). At 30 days after the injection, number of TH-positive neurons was significantly reduced in $\alpha$ Syn fibril-injected $\mathrm{Fabp3}^{+/+}$mice $\left(\mathrm{p}<0.01\right.$ vs. monomer-injected $\mathrm{Fabp}^{+/+}$mice; Fig. 3B), which was rescued in Fabp3 $3^{-/-}$counterparts ( $\mathrm{p}<0.05$ vs. fibril-injected Fabp3 $3^{+/+}$ mice; Fig. 3B).

\subsection{Fabp3 deletion attenuated exogenous $\alpha$ Syn fibril-induced formation of LB-like inclusions}

To confirm effects of Fabp3 deletion on aSyn conformational alternations, paSynpositive inclusions were quantified in the SNpc at 30 days. Consistent with the results of 
exogenously applied $\alpha$ Syn accumulation and loss of dopaminergic neurons, number of paSyn-positive inclusions was significantly reduced in $\alpha$ Syn fibril-injected Fabp $3^{-/-}$ compared to $\mathrm{Fabp3}^{+/+}$counterparts $(\mathrm{t}=2.77, \mathrm{p}<0.05$; Fig. 4A). $\alpha$ Syn-positive inclusions were also assessed by anti-filament conformation-specific $\alpha$ Syn antibody. Number of filament $\alpha$ Syn-positive inclusions was also reduced in $\alpha$ Syn fibril-injected Fabp $3^{-/-}$ compared to Fabp3 $3^{+/+}$counterparts $(\mathrm{t}=3.83, \mathrm{p}<0.01$; Fig. 4B). Notably, both paSyn and filament $\alpha$ Syn were not completely overlapped with ATTO550, indicating exogenous $\alpha$ Syn fibrils seeded endogenous $\alpha$ Syn into LB-like inclusions.

\subsection{Fabp3 deletion rescued exogenous $\alpha$ Syn fibril-induced motor impairments}

Finally, motor performance was assessed at 30 days after the injection as the results of $\alpha$ Syn pathology and loss of nigral dopaminergic neurons. In the rotarod task, two-way ANOVA detected a significant effect of strain $\left(\mathrm{F}_{(2,36)}=8.73, \mathrm{p}<0.01\right)$. Intrastriatal injection of $\alpha$ Syn fibrils impaired motor coordination in $F a b p 3^{+/+}(\mathrm{p}<0.01$ vs. PBSinjected $\mathrm{Fabp3}^{+/+}$mice) but not $\mathrm{Fabp3}^{-/-}$mice (Fig. 5A). In the beam-walking task, twoway ANOVA detected significant effects of genotype $\left(\mathrm{F}_{(1,36)}=8.71, \mathrm{p}<0.01\right)$, strain $\left(\mathrm{F}_{(2 \text {, }}\right.$ 36) $=18.01, \mathrm{p}<0.01)$, and genotype $\mathrm{x}$ strain $\left(\mathrm{F}_{(2,36)}=7.95, \mathrm{p}<0.01\right)$. Impaired motor performance was observed in $\alpha$ Syn fibril-injected Fabp $^{+/+}$mice $(\mathrm{p}<0.01$ vs. PBSinjected $\mathrm{Fabp}^{+/+}$mice; Fig. 5B). Fabp3 deletion attenuated $\alpha$ Syn fibril-induced motor impairments ( $\mathrm{p}<0.01$ vs. fibril-injected $\mathrm{Fabp3}^{+/+}$mice; Fig. 5B). 


\section{Discussion}

The monomeric species were rapidly degraded within hours while fibrillar species remained for days in cultured cells (Luk et al., 2009). Injection of $\alpha$ Syn assemblies into olfactory bulb demonstrated monomeric species are already detected beyond the injection site at 90 min after the injection while fibril species are rarely detected (Rey et al., 2013). The present study confirmed nigral intracellular monomeric aSyn were transiently increased at 1 day after the injection and followed by rapid decrease. In contrast, intracellular accumulation of fibrillar species were slowly and gradually increased over the time course, though the ATTO-positive area was lower than those of monomeric species. The monomeric aSyn could be subjected to degradation systems including ubiquitin-proteasome pathway, which are impaired by $\alpha$ Syn fibrils and aggregates followed by inclusion formation and neurotoxicity (Snyder et al., 2003; Tanik et al., 2013; McKinnon et al., 2020).

Experimental models demonstrated various patterns of aSyn propagation including synaptic transmission, receptors or exosomes mediation, and nanotubes transport (Alvarez-Erviti et al., 2011; Shrivastava et al., 2015; Abounit et al., 2016; Okuzumi et al., 2018). Intracerebral injection models revealed that pathological $\alpha$ Syn propagates cell-to-cell mainly by retrograde transport compared to anterograde one (Henderson et al., 2019). Retrograde tracing also confirmed paSyn-positive regions including the SNpc, amygdala, and cortex were also labelled with the tracer in mice after intrastriatal injection of $\alpha$ Syn fibrils (Froula et al., 2019). Mezias et al. reported that $\alpha$ Syn inclusions propagate mainly in a retrograde manner at early time then anterograde one on a several months scale (2020). Of note, FABP3 is abundantly expressed in nigral dopaminergic neurons but rarely in its terminal in the striatum (Shioda et al., 2010). Here, 
Fabp3 deletion attenuated exogenous $\alpha$ Syn accumulation in the SNpc after intrastriatal injection. Considering observations above, FABP3 is unlikely to be crucial in retrogradely striatonigral $\alpha$ Syn transport, at least over the time course in the present study. FABP3 makes complexes with $\alpha$ Syn to accumulate within nigral dopaminergic neurons under MPTP treatment (Shioda et al., 2014). Thus, FABP3 may participate in intracellular accumulation of exogenous $\alpha$ Syn after internalization, rather than striatonigral axonal transport in vivo.

We previously demonstrated Fabp3 deletion suppressed paSyn accumulation in the SNpc after intranigral fibrillar $\alpha$ Syn injection, which were antagonized by FABP3 overexpression (Yabuki et al., 2020); however, it remained unclear the deteriorating effect of FABP3 overexpression was due to whether just accumulation of exogenous $\alpha$ Syn, or seeding of endogenous species into inclusions. In the present study using ATTO550labelled exogenous $\alpha$ Syn, we first revealed Fabp3 deletion attenuated recruitment of endogenous $\alpha$ Syn into fibrils, which were identified from the observations that these inclusions were not completely overlapped with ATTO550-positive immunoreactivity. Overall, Fabp3 deletion attenuated intracellular accumulation of exogenous $\alpha$ Syn after storiatonigral transport, thereby inhibiting seeding of endogenous $\alpha$ Syn.

Since almost all nigral dopaminergic neurons express FABP3 (Shioda et al., 2014), we could not investigate differences in degrees of exogenous $\alpha$ Syn accumulation and seeding of endogenous $\alpha$ Syn between FABP3-positive and -negative population in $\mathrm{Fabp3}^{+/+}$mice. We will further investigate the role of FABP3 in $\alpha$ Syn propagation in regions expressing FABP3 with distinct neuronal population such as anterior cingulate cortex (Yamamoto et al., 2018), of which LB pathology and blood flow deficits are correlated with cognitive deficits and hallucinations, respectively (Kövari et al., 2003; 
Heitz et al., 2015). These approaches may challenge the contribution of FABP3 to the vulnerability of regions or cell population and to non-motor symptoms in synucleinpathies.

In conclusion, the present study first demonstrated that Fabp3 deletion suppressed exogenous aSyn accumulation in nigral dopaminergic neurons, using fluorophore-labelled aSyn assemblies in vivo. We also highlight its effect was accompanied by inhibition of seeding of endogenous $\alpha$ Syn into LB-like inclusions, which were positive for phosphorylated and filament forms. Fabp $3^{-/-}$mice were thus resistant to fibrillar $\alpha$ Syn-induced neurotoxicity and PD-like motor impairments. These results suggest FABP3 as a potential candidate of therapeutic target for synucleinopathies. 


\section{Experimental Procedures}

\subsection{Animals and stereotaxic surgery}

All animal studies conformed to Regulations for Animal Experiments and Related Activities at Tohoku University and approved by the Committee on Animal Experiments at Tohoku University (2017PhA-001; 2020PhA-007). We made all efforts to minimize the number of mice and their suffering. Three-month-old C57BL/6 male mice (Japan SLC, Inc., Shizuoka, Japan) were bred in a conventional environment with temperature (21$23^{\circ} \mathrm{C}$ ), humidity (50-60\%), a 12-h light-dark cycle (lights on, 9:00-21:00), and freely accessible normal chow and water. Fabp3 $3^{-/-}$mice were generated with $\mathrm{C} 57 \mathrm{BL} / 6$ background as described (Schaap et al., 1999).

After training sessions for behavioural analyses, mice were injected with monomeric or fibrillar $\alpha$ Syn assemblies bilaterally into the dorsal striatum (coordinates: AP: $+0.8 \mathrm{~mm}$, ML: $2.0 \mathrm{~mm}$, DV: $2.6 \mathrm{~mm}$ as described in Paxinos and Franklin, 2001). Under anaesthesia, mice received bilateral stereotaxic injection of ATTO550-labelled $\alpha \operatorname{Syn}(5 \mu \mathrm{g} / \mu \mathrm{L}$ in sterile PBS) at the volume of $1 \mu \mathrm{L}$ per hemisphere. Purification and ATTO550-labelling of $\alpha$ Syn strains were performed as described (Bousset et al., 2013; Peelaerts et al., 2015).

\subsection{Immunofluorescence and quantification}

Mice were intracardially perfused with $4 \%$ paraformaldehyde in phosphate buffer. Brain were post-fixed for $18-36 \mathrm{hr}$ then coronal sections $(50-\mu \mathrm{m}$ thickness) were prepared with a vibrating microtome (DTK-1000, Dosaka EM Co. Ltd., Kyoto, Japan). Immunofluorescence was performed as described (Matsuo et al., 2019). Sections were 
blocked with 5\% normal goat serum with $0.1 \%$ Triton X-100 in PBS, and incubated with primary antibodies overnight at $4^{\circ} \mathrm{C}$. The sections were then incubated with secondary antibodies for $90 \mathrm{~min}$ at room temperature and coverslipped with VECTASHIELD mounting medium (H-1000, Vector Laboratories, Burlingame, CA, USA). Primary and secondary antibodies were as follows: mouse monoclonal anti-TH (1:2000; RRID: AB_572268; Immunostar, Hudson, WI, USA), rabbit monoclonal anti-paSyn at S129 (1:2000; RRID: AB_869973; Abcam, Cambridge, UK), rabbit monoclonal anti-filament aSyn (1:1000; RRID: AB_2714215; Abcam), Alexa Fluor 405 goat anti-rabbit IgG (1:600; RRID: AB_221605; Invitrogen), and Alexa Fluor 488 goat anti-mouse IgG (1:600; RRID: AB_2534069; Invitrogen). Images were acquired by a confocal microscope TCS SP8 (Leica Microsystems, Wetzlar, Germany) and z-stacks were reconstructed to 3D images with a software LAS X (Leica Microsystems).

For quantifications, multi-channel images were converted to 8-bit grayscale ones for each channel in Fiji Image J (Ver. 1.52; NIH). All TH-positive cells in the SNpc were semi-automatically traced by a wand tool or manually surrounded when two or more cells are adjacent, and ATTO550-positive area within each TH-positive cell was measured. Pixel threshold of each image was adjusted by measurement of positive area in randomly selected 5 areas with no fluorescent signals. Results from each cell were averaged per section. All quantifications were performed by averaging the results from three sections per mice.

\subsection{Behavioural analyses}

The rotarod task was performed as described previously (Matsuo et al., 2019). In training sessions before stereotaxic surgery, mice were placed on a rod constantly rotated at 20 
rpm (ENV-576M; Med Associates, Inc., Fairfax, VT, USA) and allowed to repeat the session until the latency to fall exceeded $100 \mathrm{~s}$. Test sessions were conducted as similar to the training sessions and the latency to fall was recorded for up to $300 \mathrm{~s}$.

The beam-walking task was performed as described previously (Matsuo et al., 2019). In training sessions, mice were first placed on an inclined beam $(87 \times 0.5 \mathrm{~cm})$ at 1 cm from a goal box $(16 \times 16 \times 16 \mathrm{~cm})$ and were made to enter the box spontaneously. Sixty seconds after that, mice were placed again on the beam at $10,30,50$, and $80 \mathrm{~cm}$ from the box and were made to cross the beam from each distance. The training sessions were finished when mice reached the goal within $60 \mathrm{~s}$ for $80 \mathrm{~cm}$ traverse. In test sessions, mice were made to cross the beam at $80 \mathrm{~cm}$ from the box and the number of foot slips was counted.

\subsection{Statistical analysis}

Results were presented as box plots with whiskers showing 95th and 5th percentile. The first and the third quartiles are depicted by the bottom and the top of the box, respectively. The line within the box represents the median. Statistical analyses were performed by JASP (ver. 0.13.1; University of Amsterdam, Amsterdam, Netherlands). Statistical significance was detected using Welch's $t$-test for comparisons between two groups. For multiple-group comparisons, the significance was detected by three-way (genotype $\mathrm{x}$ strain $\mathrm{x}$ time) or two-way (genotype $\mathrm{x}$ time or genotype $\mathrm{x}$ strain) analysis of variance (ANOVA) followed by Tukey's test. Values of statistical significance were set as follows:

* when $P<0.05$ and ** when $P<0.01$. 


\section{Acknowledgments}

\section{Funding}

This work was supported by Project of Translational and Clinical Research Core Centers from Japan Agency for Medical Research and Development (AMED) [JP19dm0107071 and JP20dm0107071 to K.F.] and grants-in-aid for Scientific Research from the Ministry of Education, Science, Sports and Culture of Japan [18J20651 to K.M.].

\section{Declarations of interest}

None. 


\section{References}

Abounit, S., Bousset, L., Loria, F., Zhu, S., de Chaumont, F., Pieri, L., Olivo-Marin, J.C., Melki, R., Zurzolo, C., 2016. Tunneling nanotubes spread fibrillar $\alpha$-synuclein by intercellular trafficking of lysosomes. EMBO J. 35, 2120-2138. https://doi.org/10.15252/embj.201593411

Alvarez-Erviti, L., Seow, Y., Schapira, A.H., Gardiner, C., Sargent, I.L., Wood, M.J.A., Cooper, J.M., 2011. Lysosomal dysfunction increases exosome-mediated alphasynuclein release and transmission. Neurobiol. Dis. 42, 360-367. https://doi.org/10.1016/j.nbd.2011.01.029

Bousset, L., Pieri, L., Ruiz-Arlandis, G., Gath, J., Jensen, P.H., Habenstein, B., Madiona, K., Olieric, V., Böckmann, A., Meier, B.H., Melki, R., 2013. Structural and functional characterization of two alpha-synuclein strains. Nat. Commun. 4, 2575. https://doi.org/10.1038/ncomms3575

Braak, E., Sandmann-Keil, D., Rüb, U., Gai, W.P., de Vos, R.A.I., Jansen Steur, E.N.H., Arai, K., Braak, H., 2001. $\alpha$-Synuclein immunopositive Parkinson's disease-related inclusion bodies in lower brain stem nuclei. Acta Neuropathol. 101, 195-201. https://doi.org/10.1007/s004010000247 
Braak, H., Del Tredici, K., Rüb, U., De Vos, R.A.I., Jansen Steur, E.N.H., Braak, E., 2003. Staging of brain pathology related to sporadic Parkinson's disease. Neurobiol. Aging 24, 197-211. https://doi.org/10.1016/S0197-4580(02)00065-9

Canron, M.H., Perret, M., Vital, A., Bézard, E., Dehay, B., 2012. Age-dependent $\alpha-$ synuclein aggregation in the Microcebus murinus lemur primate. Sci. Rep. 2, 910. https://doi.org/10.1038/srep00910

Cheng, A., Shinoda, Y., Yamamoto, T., Miyachi, H., Fukunaga, K., 2019. Development of FABP3 ligands that inhibit arachidonic acid-induced $\alpha$-synuclein oligomerization. Brain Res. 1707, 190-197. https://doi.org/10.1016/j.brainres.2018.11.036

Chiasserini, D., Biscetti, L., Eusebi, P., Salvadori, N., Frattini, G., Simoni, S., De Roeck, N., Tambasco, N., Stoops, E., Vanderstichele, H., Engelborghs, S., Mollenhauer, B., Calabresi, P., Parnetti, L., 2017. Differential role of CSF fatty acid binding protein 3, $\alpha$-synuclein, and Alzheimer's disease core biomarkers in Lewy body disorders and Alzheimer's dementia. Alzheimer's Res. Ther. 9, 52. https://doi.org/10.1186/s13195-017-0276-4 
Coe, N.R., Bernlohr, D.A., 1998. Physiological properties and functions of intracellular fatty acid-binding proteins. Biochim. Biophys. Acta 1391, 287-306. https://doi.org/10.1016/S0005-2760(97)00205-1

Diao, J., Burré, J., Vivona, S., Cipriano, D.J., Sharma, M., Kyoung, M., Südhof, T.C., Brunger, A.T., 2013. Native $\alpha$-synuclein induces clustering of synaptic-vesicle mimics via binding to phospholipids and synaptobrevin-2/VAMP2. Elife 2, e00592. https://doi.org/10.7554/eLife.00592

Erskine, D., Patterson, L., Alexandris, A., Hanson, P.S., McKeith, I.G., Attems, J., Morris, C.M., 2018. Regional levels of physiological $\alpha$-synuclein are directly associated with Lewy body pathology. Acta Neuropathol. 135, 153-154. https://doi.org/10.1007/s00401-017-1787-6

Froula, J.M., Castellana-Cruz, M., Anabtawi, N.M., Camino, J.D., Chen, S.W., Thrasher, D.R., Freire, J., Yazdi, A.A., Fleming, S., Dobson, C.M., Kumita, J.R., Cremades, N., Volpicelli-Daley, L.A., 2018. Defining $\alpha$-synuclein species responsible for Parkinson's disease phenotypes in mice. J. Biol. Chem. 294, 10392-10406. https://doi.org/10.1074/jbc.RA119.007743 
Heitz, C., Noblet, V., Cretin, B., Philippi, N., Kremer, L., Stackfleth, M., Hubele, F., Armspach, J.P., Namer, I., Blanc, F., 2015. Neural correlates of visual hallucinations in dementia with Lewy bodies. Alzheimer's Res. Ther. 7, 6. https://doi.org/10.1186/s13195-014-0091-0

Henderson, M.X., Cornblath, E.J., Darwich, A., Zhang, B., Brown, H., Gathagan, R.J., Sandler, R.M., Bassett, D.S., Trojanowski, J.Q., Lee, V.M.Y., 2019. Spread of $\alpha-$ synuclein pathology through the brain connectome is modulated by selective vulnerability and predicted by network analysis. Nat. Neurosci. 22, 1248-1257. https://doi.org/10.1038/s41593-019-0457-5

Hertzel, A.V., Bernlohr, D.A., 2000. The mammalian fatty acid-binding protein multigene family: molecular and genetic insights into function. Trends Endocrinol. Metab. 11, 175-180. https://doi.org/10.1016/S1043-2760(00)00257-5

Kawahata, I., Bousset, L., Melki, R., Fukunaga, K., 2019. Fatty acid-binding protein 3 is critical for $\alpha$-synuclein uptake and $\mathrm{MPP}^{+}$-induced mitochondrial dysfunction in cultured dopaminergic neurons. Int. J. Mol. Sci. 20, 5358. https://doi.org/10.3390/ijms20215358 
Kordower, J.H., Chu, Y., Hauser, R.A., Freeman, T.B., Olanow, C.W., 2008. Lewy bodylike pathology in long-term embryonic nigral transplants in Parkinson's disease. Nat. Med. 14, 504-506. https://doi.org/10.1038/nm1747

Kövari, E., Gold, G., Herrmann, F.R., Canuto, A., Hof, P.R., Bouras, C., Giannakopoulos, P., 2003. Lewy body densities in the entorhinal and anterior cingulate cortex predict cognitive deficits in Parkinson's disease. Acta Neuropathol. 106, 83-88. https://doi.org/10.1007/s00401-003-0705-2

Luk, K.C., Song, C., O’Brien, P., Stieber, A., Branch, J.R., Brunden, K.R., Trojanowski, J.Q., Lee, V.M.Y., 2009. Exogenous $\alpha$-synuclein fibrils seed the formation of Lewy body-like intracellular inclusions in cultured cells. Proc. Natl. Acad. Sci. U. S. A. 106, 20051-20056. https://doi.org/10.1073/pnas.0908005106

Maroteaux, L., Campanelli, J.T., Scheller, R.H., 1988. Synuclein: a neuron-specific protein localized to the nucleus and presynaptic nerve terminal. J. Neurosci. 8, 28042815. https://doi.org/10.1523/jneurosci.08-08-02804.1988

Matsuo, K., Cheng, A., Yabuki, Y., Takahata, I., Miyachi, H., Fukunaga, K., 2019. Inhibition of MPTP-induced $\alpha$-synuclein oligomerization by fatty acid-binding 
protein 3 ligand in MPTP-treated mice. Neuropharmacology 150, 164-174. https://doi.org/10.1016/j.neuropharm.2019.03.029

McKinnon, C., De Snoo, M.L., Gondard, E., Neudorfer, C., Chau, H., Ngana, S.G., O’Hara, D.M., Brotchie, J.M., Koprich, J.B., Lozano, A.M., Kalia, L.V., Kalia, S.K., 2020. Early-onset impairment of the ubiquitin-proteasome system in dopaminergic neurons caused by $\alpha$-synuclein. Acta Neuropathol. Commun. 8, 17. https://doi.org/10.1186/s40478-020-0894-0

Mezias, C., Rey, N., Brundin, P., Raj, A., 2020. Neural connectivity predicts spreading of alpha-synuclein pathology in fibril-injected mouse models: Involvement of retrograde and anterograde axonal propagation. Neurobiol. Dis. 134, 104623. https://doi.org/10.1016/j.nbd.2019.104623

Mollenhauer, B., Steinacker, P., Bahn, E., Bibl, M., Brechlin, P., Schlossmacher, M.G., Locascio, J.J., Wiltfang, J., Kretzschmar, H.A., Poser, S., Trenkwalder, C., Otto, M., 2007. Serum heart-type fatty acid-binding protein and cerebrospinal fluid tau: marker candidates for dementia with Lewy bodies. Neurodegener. Dis. 4, 366-375. https://doi.org/10.1159/000105157 
Okuzumi, A., Kurosawa, M., Hatano, T., Takanashi, M., Nojiri, S., Fukuhara, T., Yamanaka, T., Miyazaki, H., Yoshinaga, S., Furukawa, Y., Shimogori, T., Hattori, N., Nukina, N., 2018. Rapid dissemination of alpha-synuclein seeds through neural circuits in an in-vivo prion-like seeding experiment. Acta Neuropathol. Commun. 6, 96. https://doi.org/10.1186/s40478-018-0587-0

Owada, Y., Yoshimoto, T., Kondo, H., 1996. Spatio-temporally differential expression of genes for three members of fatty acid binding proteins in developing and mature rat brains. J. Chem. Neuroanat. 12, 113-122. https://doi.org/10.1016/S08910618(96)00192-5

Paumier, K.L., Luk, K.C., Manfredsson, F.P., Kanaan, N.M., Lipton, J.W., Collier, T.J., Steece-Collier, K., Kemp, C.J., Celano, S., Schulz, E., Sandoval, I.M., Fleming, S., Dirr, E., Polinski, N.K., Trojanowski, J.Q., Lee, V.M., Sortwell, C.E., 2015. Intrastriatal injection of pre-formed mouse $\alpha$-synuclein fibrils into rats triggers $\alpha$ synuclein pathology and bilateral nigrostriatal degeneration. Neurobiol. Dis. 82, 185-199. https://doi.org/10.1016/j.nbd.2015.06.003

Paxinos, G., Franklin, K.B.J., 2001. The Mouse Brain in Stereotaxic Coordinates, 2nd edition, Academic Press. 
Peelaerts, W., Bousset, L., Van Der Perren, A., Moskalyuk, A., Pulizzi, R., Giugliano, M., Van Den Haute, C., Melki, R., Baekelandt, V., 2015. $\alpha$-Synuclein strains cause distinct synucleinopathies after local and systemic administration. Nature 522, 340344. https://doi.org/10.1038/nature14547

Perrin, R.J., Woods, W.S., Clayton, D.F., George, J.M., 2001. Exposure to long chain polyunsaturated fatty acids triggers rapid multimerization of synucleins. J. Biol. Chem. 276, 41958-41962. https://doi.org/10.1074/jbc.M105022200

Qin, Z., Hu, D., Han, S., Reaney, S.H., Di Monte, D.A., Fink, A.L., 2007. Effect of 4hydroxy-2-nonenal modification on $\alpha$-synuclein aggregation. J. Biol. Chem. 282, 5862-5870. https://doi.org/10.1074/jbc.M608126200

Rey, N.L., Petit, G.H., Bousset, L., Melki, R., Brundin, P., 2013. Transfer of human $\alpha-$ synuclein from the olfactory bulb to interconnected brain regions in mice. Acta Neuropathol. 126, 555-573. https://doi.org/10.1007/s00401-013-1160-3 
Schaap, F.G., Binas, B., Danneberg, H., van der Vusse, G.J., Glatz, J.F.C., 1999. Impaired long-chain fatty acid utilization by cardiac myocytes isolated from mice lacking the heart-type fatty acid binding protein gene. Circ. Res. 85, 329-337. https://doi.org/10.1161/01.RES.85.4.329

Sharon, R., Bar-Joseph, I., Frosch, M.P., Walsh, D.M., Hamilton, J.A., Selkoe, D.J., 2003. The formation of highly soluble oligomers of $\alpha$-synuclein is regulated by fatty acids and enhanced in Parkinson's disease. Neuron 37, 583-595. https://doi.org/10.1016/S0896-6273(03)00024-2

Shioda, N., Yamamoto, Y., Watanabe, M., Binas, B., Owada, Y., Fukunaga, K., 2010. Heart-type fatty acid binding protein regulates dopamine D2 receptor function in mouse brain. $\quad$ J. $\quad$ Neurosci. $\quad 30, \quad 3146-3155$. https://doi.org/10.1523/JNEUROSCI.4140-09.2010

Shioda, N., Yabuki, Y., Kobayashi, Y., Onozato, M., Owada, Y., Fukunaga, K., 2014. FABP3 protein promotes $\alpha$-synuclein oligomerization associated with 1-Methyl1,2,3,6-tetrahydropiridine-induced neurotoxicity. J. Biol. Chem. 289, 18957-18965. https://doi.org/10.1074/jbc.M113.527341 
Shrivastava, A.N., Redeker, V., Fritz, N., Pieri, L., Almeida, L.G., Spolidoro, M., Liebmann, T., Bousset, L., Renner, M., Léna, C., Aperia, A., Melki, R., Triller, A., 2015. $\alpha$-synuclein assemblies sequester neuronal $\alpha 3-\mathrm{Na}^{+} / \mathrm{K}^{+}$-ATPase and impair $\mathrm{Na}^{+}$ gradient. EMBO J. 34, 2408-2423. https://doi.org/10.15252/embj.201591397

Snyder, H., Mensah, K., Theisler, C., Lee, J., Matouschek, A., Wolozin, B., 2003. Aggregated and monomeric $\alpha$-synuclein bind to the $\mathrm{S}^{\prime}$ ' proteasomal protein and inhibit proteasomal function. J. Biol. Chem. 278, 11753-11759. https://doi.org/10.1074/jbc.M208641200

Spillantini, M.G., Schmidt, M.L., Lee, V.M.Y., Trojanowski, J.Q., Jakes, R., Goedert, M., 1997. $\alpha$-synuclein in Lewy bodies. Nature 388, 839-840. https://doi.org/10.1038/42166

Tanik, S.A., Schultheiss, C.E., Volpicelli-Daley, L.A., Brunden, K.R., Lee, V.M.Y., 2013. Lewy body-like $\alpha$-synuclein aggregates resist degradation and impair macroautophagy. J. Biol. Chem. 288, 15194-15210. https://doi.org/10.1074/jbc.M113.457408 
Wada-Isoe, K., Imamura, K., Kitamaya, M., Kowa, H., Nakashima, K., 2008. Serum heart-fatty acid binding protein levels in patients with Lewy body disease. J. Neurol. Sci. 266, 20-24. https://doi.org/10.1016/j.jns.2007.08.018

Winner, B., Jappelli, R., Maji, S.K., Desplats, P.A., Boyer, L., Aigner, S., Hetzer, C., Loher, T., Vilar, M., Campioni, S., Tzitzilonis, C., Soragni, A., Jessberger, S., Mira, H., Consiglio, A., Pham, E., Masliah, E., Gage, F.H., Riek, R., 2011. In vivo demonstration that $\alpha$-synuclein oligomers are toxic. Proc. Natl. Acad. Sci. U. S. A. 108, 4194-4199. https://doi.org/10.1073/pnas.1100976108

Yabuki, Y., Matsuo, K., Kawahata, I., Fukui, N., Mizobata, T., Kawata, Y., Owada, Y., Shioda, N., Fukunaga, K., 2020. Fatty acid binding protein 3 enhances the spreading and toxicity of $\alpha$-synuclein in mouse brain. Int. J. Mol. Sci. 21, 2230. https://doi.org/10.3390/ijms21062230

Yakunin, E., Loeb, V., Kisos, H., Biala, Y., Yehuda, S., Yaari, Y., Selkoe, D.J., Sharon, R., 2012. $\alpha$-Synuclein neuropathology is controlled by nuclear hormone receptors and enhanced by docosahexaenoic acid in a mouse model for Parkinson's disease. Brain Pathol. 22, 280-294. https://doi.org/10.1111/j.1750-3639.2011.00530.x 
Yamamoto, Y., Kida, H., Kagawa, Y., Yasumoto, Y., Miyazaki, H., Islam, A., Ogata, M., Yanagawa, Y., Mitsushima, D., Fukunaga, K., Owada, Y., 2018. FABP3 in the anterior cingulate cortex modulates the methylation status of the glutamic acid decarboxylase 67 promoter region. J. Neurosci. 38, 10411-10423. https://doi.org/10.1523/JNEUROSCI.1285-18.2018 
Figure Legends

Fig. 1 Experimental schedule.

Experimental schedule in this study. Mice were divided into two groups and subjected to experiment 1 and 2.

Fig. 2 Effects of Fabp3 deletion on exogenous $\alpha$ Syn accumulation in the SNpc after intrastriatal injection.

ATTO550-positive area (magenta) per TH-positive cells (cyan) were quantified at indicated days after monomeric (A) or fibrillar (B) aSyn injection, respectively. No paSyn-positive immunoreactivity (yellow) was observed in monomeric $\alpha$ Syn-injected group (A) while LB-like inclusions were formed from 10 days after fibrillar $\alpha$ Syn injection (B). Scale bar: $10 \mu \mathrm{m}$. The bottom and the top of the box represent the first and the third quartiles, respectively. The line within the box depicts the median. Two whiskers represent 95 th and 5th percentile. Statistical differences were detected by two-way ANOVA followed by post-hoc Tukey's test; ${ }^{* *} \mathrm{p}<0.01$ for $\alpha$ Syn monomer-injected Fabp $^{+/+}$vs. Fabp3 $3^{-/-}$mice ( $=5$ per group) in (A); ${ }^{*} \mathrm{p}<0.05$ and ${ }^{* *} \mathrm{p}<0.01$ for $\alpha$ Syn fibril-injected $\mathrm{Fabp3}^{+/+}$vs. Fabp3 $3^{-/-}$mice (n $=5$ per group) in (B).

Fig. 3 Effects of Fabp3 deletion on loss of dopaminergic neurons in the SNpc after intrastriatal injection of $\alpha$ Syn fibrils.

(A) Representative images of TH-positive cells (cyan) in the SNpc at 30 days after the injection. Images from PBS-injected groups were represented as reference controls. The dashed line indicates the boundary between SNpc and VTA. Scale bar: $250 \mu \mathrm{m}$. (B) 
Quantifications for TH-positive cells in the SNpc at indicated days after the injection. The bottom and the top of the box represent the first and the third quartiles, respectively. The line within the box depicts the median. Two whiskers represent 95th and 5th percentile. Statistical differences were detected by three-way ANOVA followed by post-hoc Tukey's test; ${ }^{* *} \mathrm{p}<0.01$ for $\alpha$ Syn monomer-injected vs. fibrillar-injected $\mathrm{Fabp}^{+/+}$; ${ }^{\#} \mathrm{p}<0.05$ for $\alpha$ Syn fibril-injected $\mathrm{Fabp}^{+/+}$vs. Fabp $3^{-/-}$mice (n $=5$ per group). VTA, ventral tegmental area

Fig. 4 Effects of Fabp3 deletion on the formation of LB-like inclusions in the SNpc after intrastriatal injection of $\alpha$ Syn fibrils.

aSyn-positive inclusions were assessed using paSyn-specific (yellow; A) and filament aSyn-specific (yellow; B) antibodies. Sections were co-stained with anti-TH antibody (cyan) and ATTO550-positive immunoreactivity (magenta) was directly visualized. Scale bar: $10 \mu \mathrm{m}$. The bottom and the top of the box represent the first and the third quartiles, respectively. The line within the box depicts the median. Two whiskers represent 95 th and 5th percentile. Statistical differences were detected by Welch's $t$-test; ${ }^{*} \mathrm{p}<0.05$ and ${ }^{* *} \mathrm{p}<$ 0.01 for $\alpha$ Syn fibril-injected $\mathrm{Fabp}^{+/+}$vs. Fabp $3^{-/-}$mice (n $=5$ per group).

Fig. 5 Effects of Fabp3 deletion on motor impairments after intrastriatal injection of $\alpha$ Syn fibrils.

(A) Latency to fall from a rod in a rotarod task ( $n=7$ per group). (B) Error number of steps in a beam-walking task ( $\mathrm{n}=7$ per group). The bottom and the top of the box represent the first and the third quartiles, respectively. The line within the box depicts the median. Two whiskers represent 95 th and 5 th percentile. Statistical differences were 
detected by two-way ANOVA followed by post-hoc Tukey's test; ${ }^{* *} \mathrm{p}<0.01$ for PBSinjected vs. $\alpha$ Syn fibril-injected $\mathrm{Fabp}^{+/+}$mice; ${ }^{\# \#} \mathrm{p}<0.01$ for $\alpha$ Syn fibril-injected $\mathrm{Fabp3}^{+/+}$vs. Fabp $3^{-/-}$mice. n.s., not significant. 
Experiment 1

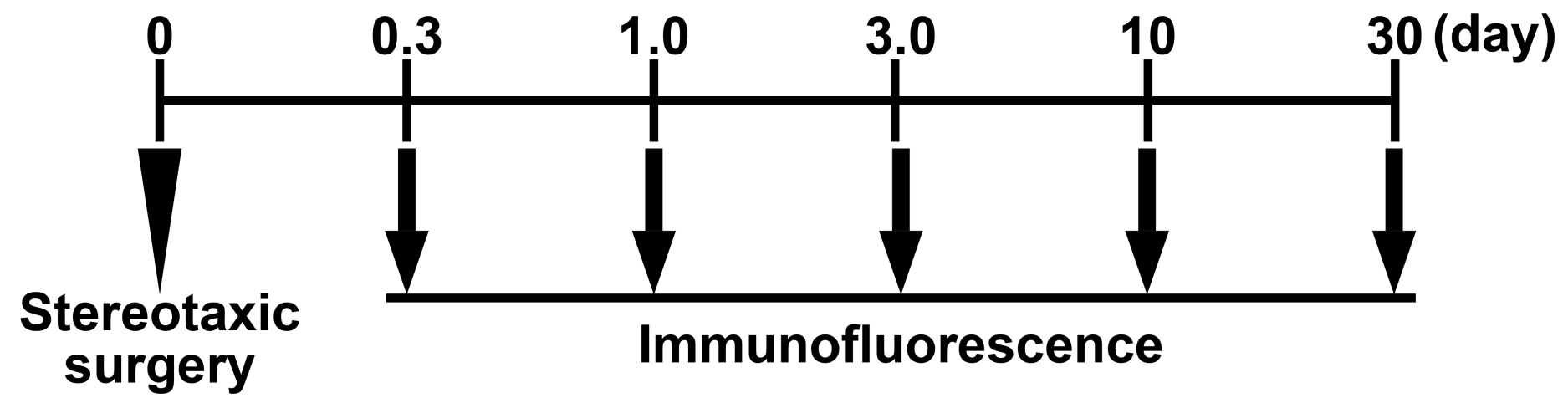

Experiment 2

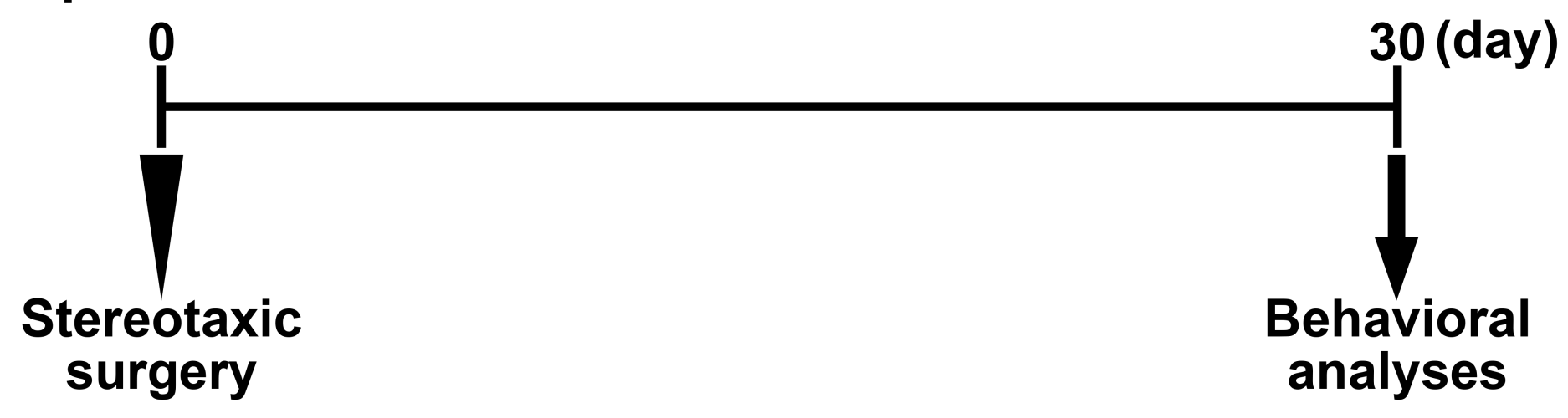


A Monomer

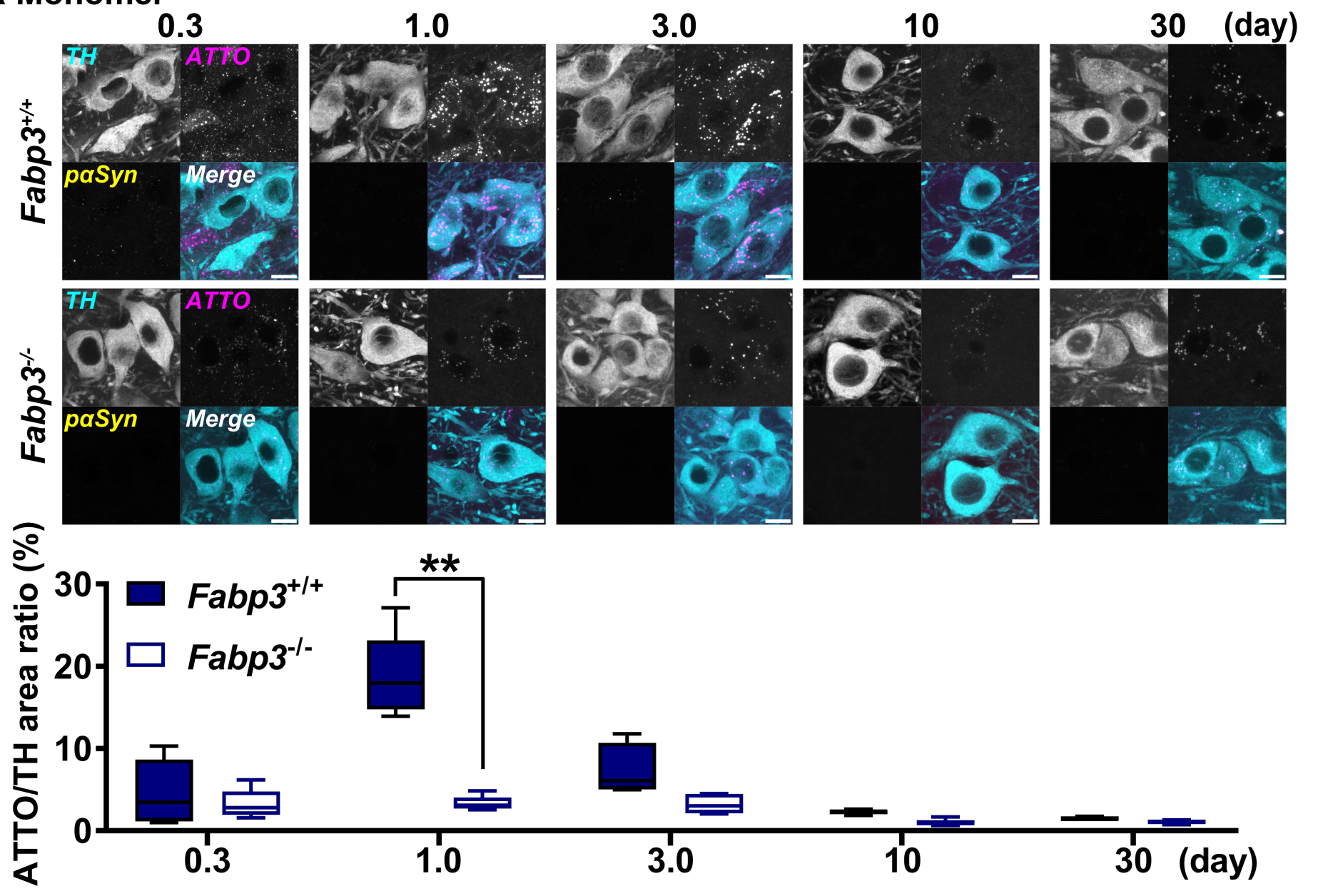

B Fibril
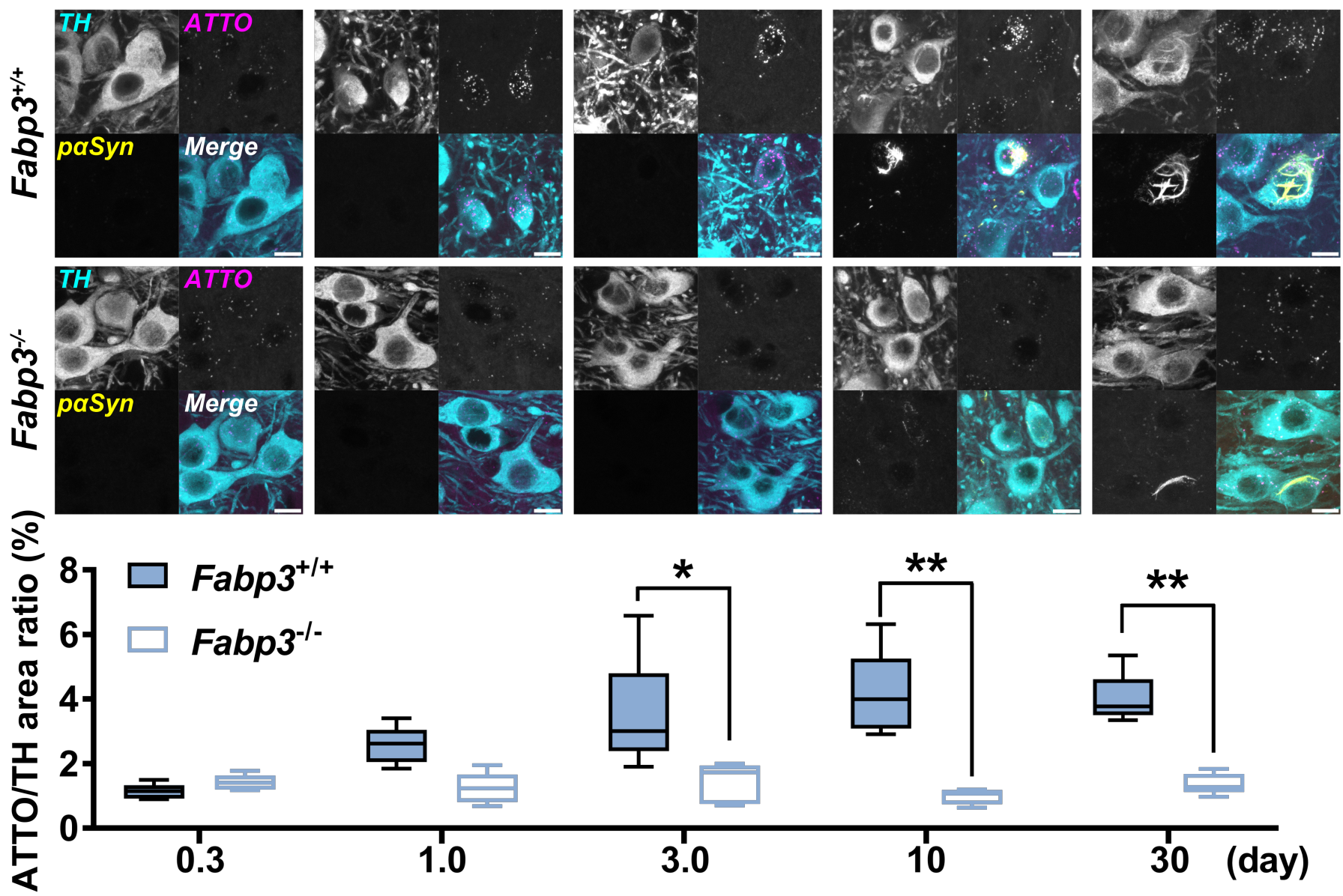


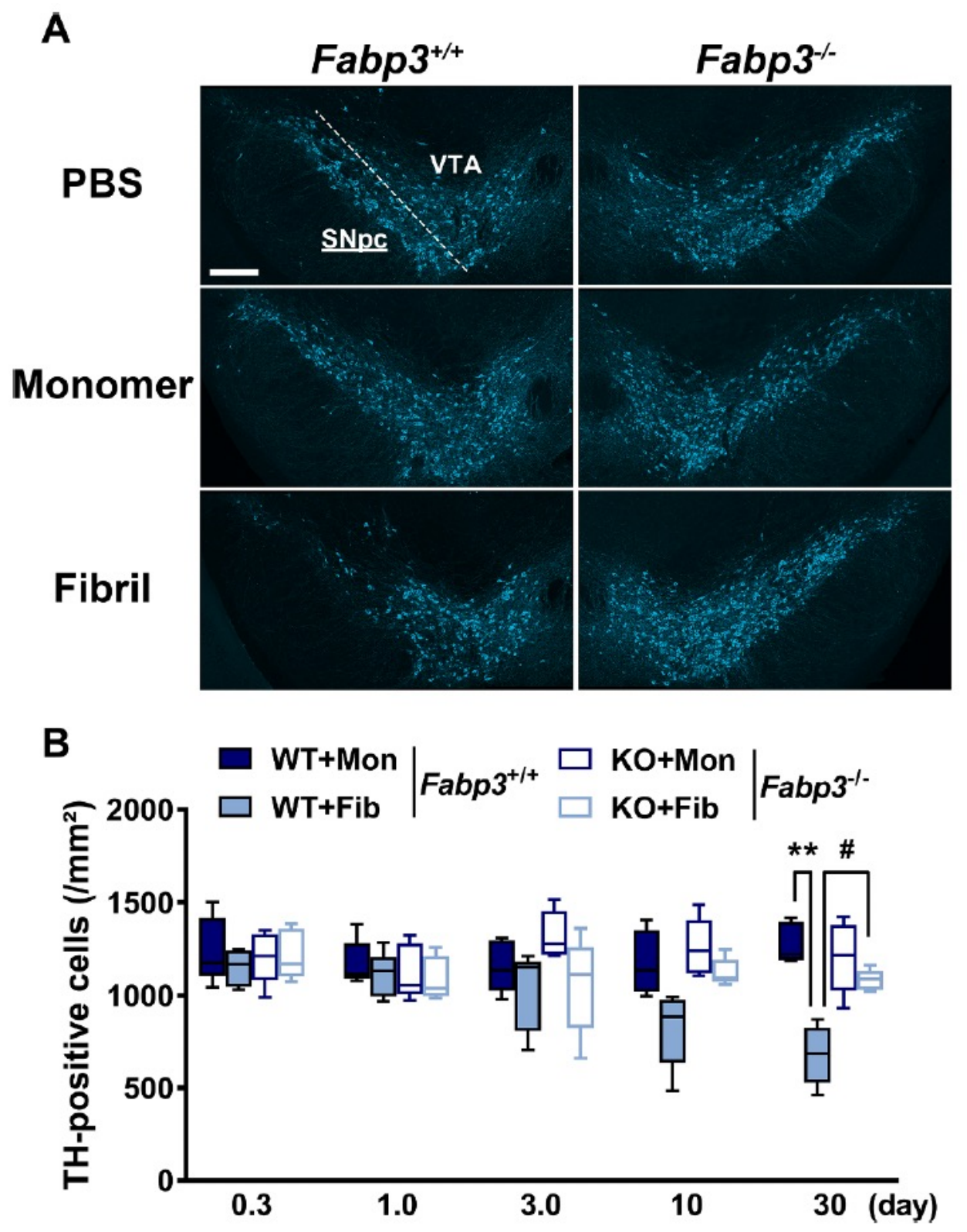



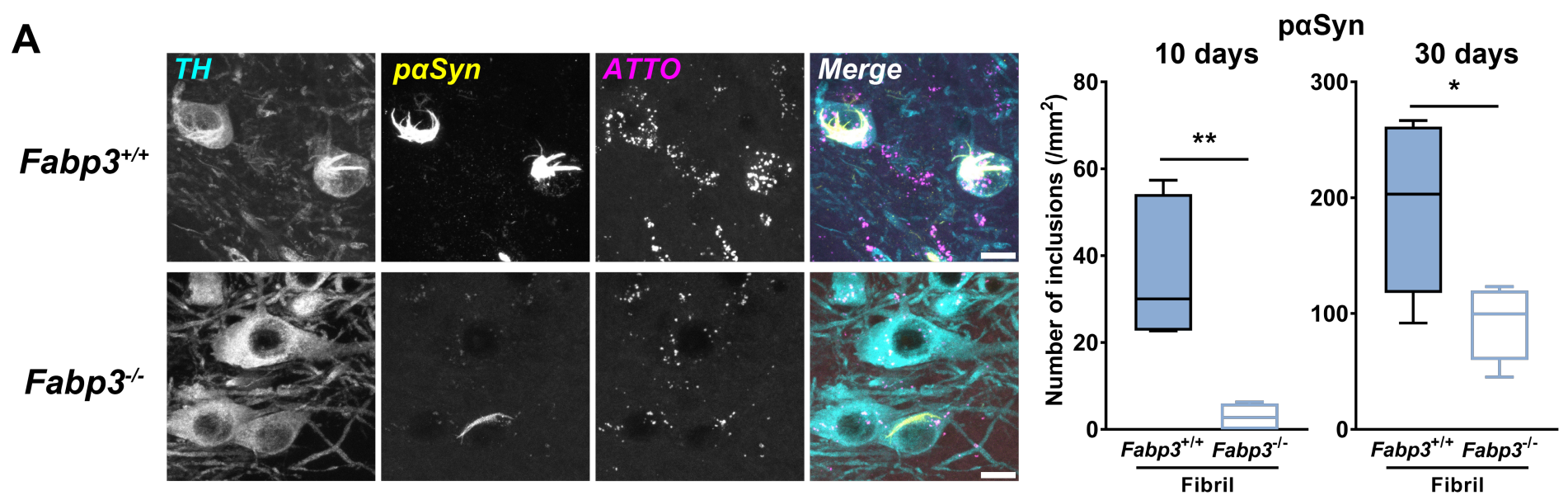

B

Fabp3 $^{+/+}$
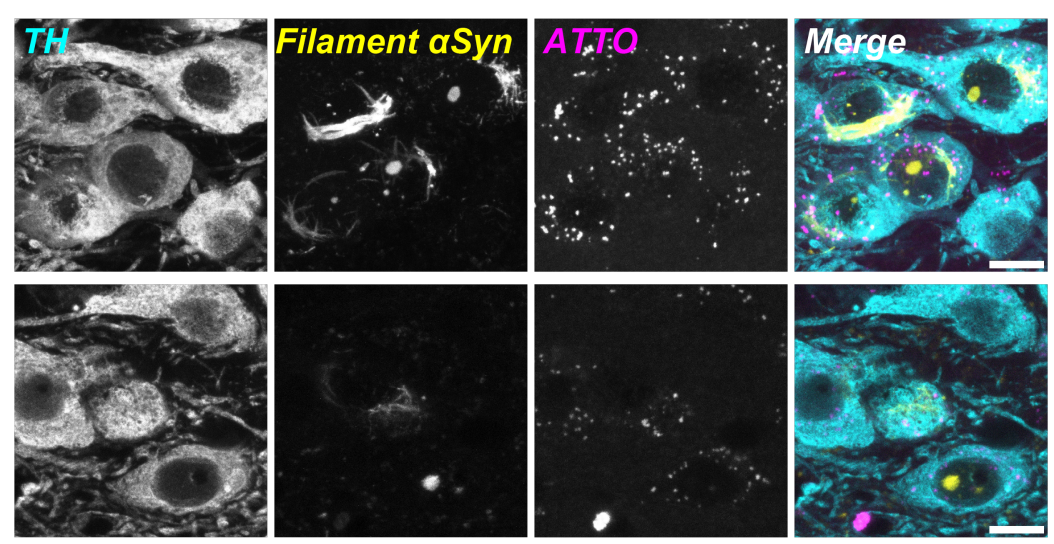

Filament $\alpha$ Syn (30 days)

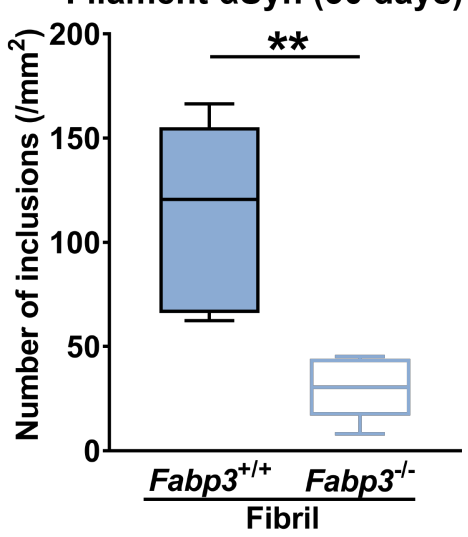



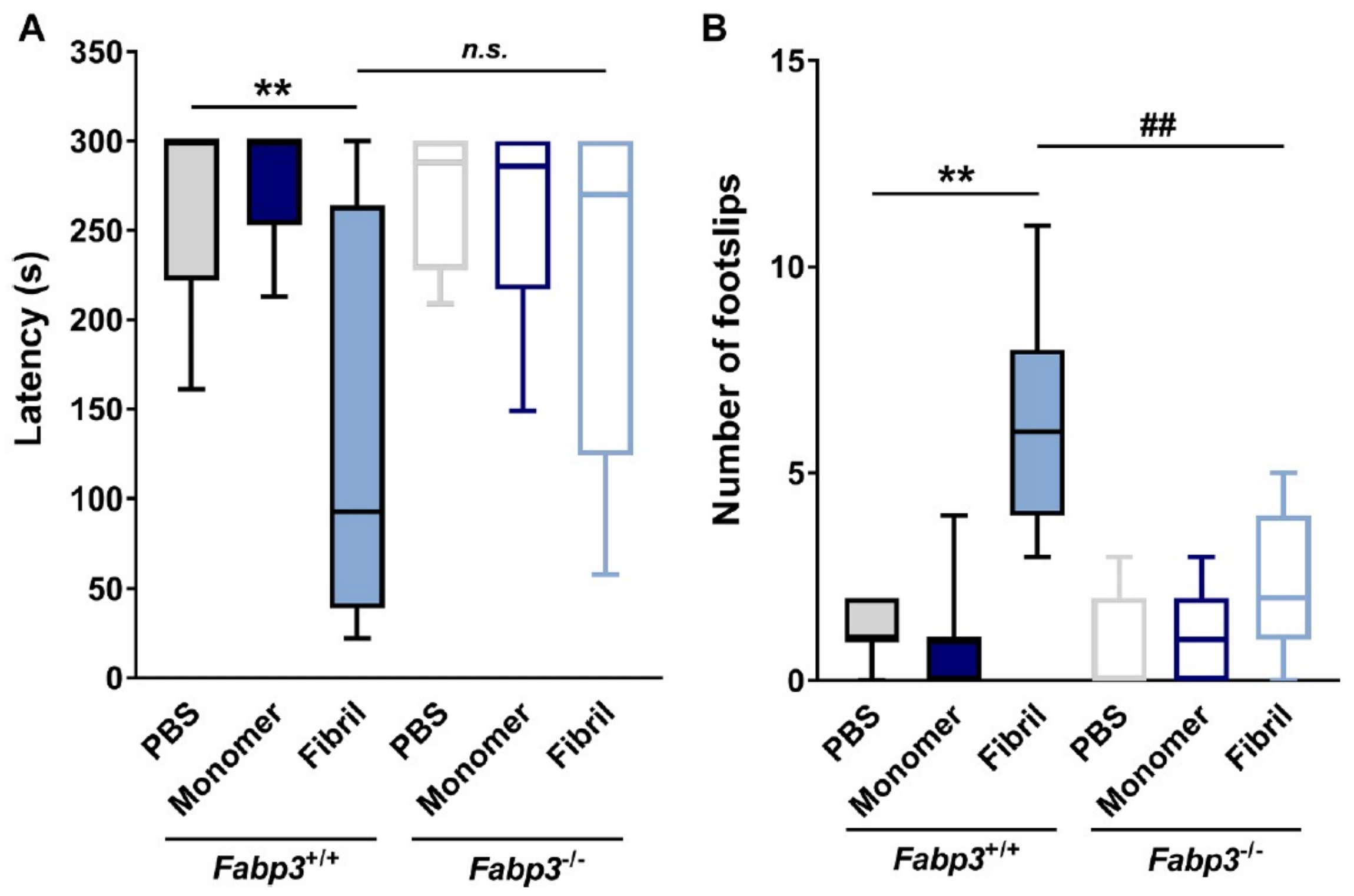